\title{
Correlations between Chemistry Lab Notebooks Scores and Academic Achievement Scores of Gifted Science Students and Their Perceptions on Chemistry Lab and the Lab Notebooks

\author{
Dong-Jin Kim, Kuk-Tae Park, Denise Pentland
}

Jowon High School, 15, Suil-ro 233beon-gil, Jangan-gu, Suwon-si, Gyeonggi-do, 440-843, South Korea

sunjinandsojin@hanmail.net

Department of Chemistry Education, Korea National University of Education, Chongwon-gun, Chungbuk

363-791, South Korea

ktpark@ knue.ac.kr

Prudhoe Community High School (PCHS), Moor Road, Prudhoe, Northumberland, NE42 5LJ, United Kingdom

Denise.Pentland@northumberland.gov.uk

\begin{abstract}
The purpose of this study is to analyze chemistry laboratory notebooks completed by gifted science students and their observations on chemistry experiments and the laboratory notebooks, focusing on the correlations among the students' mid-term academic achievement (MAA) scores, the holistic grading scale (HGS) and lab note rubric (LNR) scores for their chemistry laboratory notebooks. Through an e-mail questionnaire, the gifted science students, now attending universities, gave their opinion on the value of the chemistry experiments and the laboratory notebooks they wrote in their high school days. Based on the correlations between the students mid-term scores and their chemistry experiment laboratory notebook scores, the students were divided into four groups and one student from each group was selected for a semi-structured telephone interview. The results of the study revealed that the MAA scores and chemistry LNR scores are more correlated than the MAA scores and chemistry HGS scores and the students from every group felt that they gained a better understanding of experimental procedures and data analysis by doing laboratory experiments. All of them think that completing the chemistry laboratory notebook in science high school and university is very useful for studies in advanced chemistry.
\end{abstract}

\section{Indexing terms/Key words}

Gifted science student, chemistry experiment, chemistry experiments laboratory notebook, science high school

\section{Academic Discipline and Sub-Disciplines}

Chemical Education

\section{SUBJECT CLASSIFICATION}

Chemistry Subject Classification

\section{TYPE (METHOD/APPROACH)}

Survey/Interview

\section{Council for Innovative Research}

Peer Review Research Publishing System

Journal: INTERNATIONAL JOURNAL OF RESEARCH IN EDUCATION METHODOLOGY

Vol. 6, No. 2

www.ijrem.com , ijremeditor@gmail.com 


\section{INTRODUCTION}

The chemistry teacher has a real challenge in teaching his or her subject matter because chemistry is considered by many otherwise bright students to be an abstract and difficult subject. Since chemistry lab experiments are important in the science high school, gifted science students should have a grasp of the chemistry knowledge as well as the communication skills required for chemistry laboratories. The lab exploration enhances the skills and ability to perform scientific experiments. In high school chemistry classes, in general, the procedure to be followed for any laboratory activity is either designed by the students or provided to them from an external source (the instructor, a laboratory manual, or a handout). Inquiry and problem-based methods ask the students to develop their own procedures. Scientific laboratory with working inquiry has been a continual objective in science education, especially for helping students to develop adequate conceptions of the nature of science (National Research Council [NRC], 1996; NRC, 2000; American Association for the Advancement of Science [AAAS], 1993).

As a matter of science philosophy, the students should understand that chemists must perform experiments and record and interpret the results of experiments to understand chemistry (Cacciatore \& Sevian, 2006; Dodd, 1997; Kanare, 1985). Lab notebooks must be used as the standard format, which is described next, for reports of original research but not necessarily for literature reviews or theoretical papers. Interpreting experimental data and articulating the broader meanings of the data are essential components of the discourse of science. Lab notebooks are vehicles for organizing the thoughts and ideas of the writer, as well as the receptacles for detailed procedural information that might not be available in highly compressed journal articles (Eisenberg, 1982). Students dislike writing the lab notebook because it can be tedious and time-consuming. Instructors dislike teaching how to write the lab notebook because it significantly increases their grading load. For these reasons, lab reports are often omitted or replaced by alternatives such as responses to lab questions, fill-in-the-blank lab manual exercises, or lab quizzes. Students, even at the college level, have difficulties interpreting graphs and tying scientific data to science concepts. Students are also more apt to revisit the lab procedure and reflect on the experiment when writing the lab report. Reflecting on the lab in conjunction with putting the lab in their own words provides students with a very effective tool for learning the science of the lab (Berg et al, 2003; Ferzli, 2005). Careful checking does teach the student the value of recording all data and observations in the notebooks. Laboratory notebooks are sometimes used as the basis for assessing the lab work and are often graded using a pass-fail system and are sometimes used in conjunction with laboratory reports (Baird, 1995; Beall \& Trimbur, 2001; Wimpfheimer, 2004 ). Good writing of the chemistry laboratory notebook should be a matter of habit, not a chore. Therefore, chemistry laboratory notebook writing should be taught at an early age before the students begin a scientific career. Besides the undergraduate chemistry course need to writing activity in facilitating student chemistry learning (Vázquez, 2012)

To investigate the correlations between mid-term academic achievement (MAA) scores and the holistic grading scale (HGS) scores as well as the correlations between the MAA scores and the lab note rubric (LNR) scores, we taught a pilot chemistry course in which ninety eight $11^{\text {th }}$ grade gifted science students attending Gyeonggi Science High School at Suwon, Korea were required to complete the experiment and write an individual pre-lab note and a post-lab note in a chemistry experiment laboratory notebook. After they graduated from science high school and went on to universities to continue their advanced studies, a questionnaire survey was conducted to examine the perceptions of gifted science students of chemistry experiments and the laboratory notebooks - the perceptions they acquired while they were taking the pilot chemistry class in science high school.

\section{METHOD}

\section{Participants}

Ninety eight $11^{\text {th }}$ grade gifted science students attending Gyeonggi Science High School at Suwon, Korea participated in our study. The Gyeonggi Science High School selects and educates students especially talented in mathematics and sciences. After graduation, most of them go to engineering schools at Seoul National University, KAIST, Postech and other prestigious universities in Korea and in other countries, and some of them choose medical schools in Korea. Gifted science students thus form a significant minority of around $1 \%$ in the total student population (Kim et al., 2009; Lang et al., 2005; Um, 2007). Participants are divided into 2-4 member groups of $11^{\text {th }}$ grade students. All the students enrolled in the chemistry experiment class, which meets for two consecutive hours per week, complete four laboratory experimental tasks as part of their semester coursework. The participants are five groups of $11^{\text {th }}$ grade students (Table 1).

Table 1. Participants of five classes for chemistry experiment laboratory

\begin{tabular}{cccc}
\hline Class & Female & Male & Total \\
\hline 1st & 6 & 14 & 20 \\
\hline 2nd & 6 & 14 & 20 \\
\hline 3rd & 6 & 14 & 20 \\
\hline 4 th & 6 & 13 & 19 \\
\hline 5 th & 5 & 14 & 19 \\
\hline
\end{tabular}




\section{DESIGN OF INSTRUMENTS}

\section{Chemistry Experiments and Laboratory Notebook}

To analyze chemistry experiment laboratory notebooks written by gifted science students, three subjects of chemical experiments were chosen (1) measuring the density of ethanol (95\%) and copper (copper shot of 99.9\% purity), (2) determining the molecular weight of isopropyl alcohol (99.9\%) by ideal gas equation, and (3) determining the chemical formula of copper (II) sulfate pentahydrate $(99 \%)$. These experiments are available in most laboratory manuals for general chemistry. Reagents were purchased from Duksan Pure Chemical Co. Ltd.

Compared to ordinary high school students, gifted science students are instructed to do much better in lab planning. That means reading the instructions for the experiment before starting the experiment, discussing them with the lab partners, asking the instructor whatever questions one might have, knowing what data is to be collected and how to use the apparatus properly. The students are required to write the following parts ahead of time in the lab notebook: title, purpose, and plan. After the experiment is over, students are asked to do any necessary calculations and formulate a conclusion. They will then record them in a laboratory notebook which will be evaluated by the instructor. These procedures are similar to what researchers do in a company to write a lab report in industry. Writing a lab notebook was assigned in a chemistry lab class. Subjects of chemical experiments were assigned for science gifted students to do the labs; as the students did their labs, they also wrote their own procedures and results. The students, working in groups, completed the experiment and wrote an individual pre-lab note and post-lab note in a chemistry experiment laboratory notebook. Not all experiments will require a laboratory notebook, but learning how to write a good laboratory notebook is an essential component of this course.

\section{HGS for chemistry experiment}

"Introduction to writing the chemistry experiment lab notebook" was guided to evaluate chemistry experiment laboratory notebooks written by gifted science students. The relationship between the lab notebook scores and the academic achievements were analyzed. HGS and LNR were used as the criteria for evaluating the lab notebook scores. HGS was revised and supplemented to be used as an aid in applying the grading scale and as a worksheet for analyzing contents related to laboratory chemistry notebook (Goodman \& Bean, 1983). The lab notebooks are critiqued and graded (on a 5 -point holistic scale) by a chemistry teacher, using a revised grading worksheet (Goodman \& Bean, 1983). Four chemistry teachers decided to use the holistic grading scale $(1.0=$ very poor, $2.0=$ poor, $3.0=$ neutral, $4.0=$ good, $5.0=$ very good) because they agreed that the laboratory skill and the ability of science gifted students were satisfactory. The data was analyzed by Microsoft Office Excel 2007 and SPSS 12.0 for Windows.

\section{LNR for Chemistry Experiment}

Laboratory notebook should be free from spelling and grammar errors and all writing should be in complete sentences. On the Model for developing a scoring team, detailed scoring procedures provide high inter-rater agreement among independent raters of the same 14 gifted science students (Doran, et al., 1998). The level of inter-rater reliability of LNR score for chemistry experiment was determined by the percentage of agreement among the three independent raters. Three science teachers agreed on 15 criteria to be used. Three independent raters are a chemistry teacher (7 years of teaching experience), an earth science teacher (23 years of teaching experience), and chemistry teacher (12 years of teaching experience). So the percent of agreement was $100 \%$ for the LNR scoring (Table 2). As shown in Table 2, LNR scoring was consists of 5 sections and 15 criteria (Shiland, 1999).

Table 2. LNR (Shiland, 1999)

\begin{tabular}{|c|c|c|c|}
\hline Section & Number & Criteria & Points $^{2}$ \\
\hline \multirow{3}{*}{ Introduction } & 1 & Title, number and date of lab & 1 \\
\hline & 2 & Object statement & 2 \\
\hline & 3 & Apparatus, reagent, theoretical background of lab & 2 \\
\hline \multirow{6}{*}{ Method } & 4 & $\begin{array}{l}\text { Complete sentences procedure, calculation guide, draw a labeled procedure } \\
\text { diagram }\end{array}$ & 10 \\
\hline & 5 & Equipment listed with diagram & 2 \\
\hline & 6 & Safety, caution & 2 \\
\hline & 7 & Changes in procedure indicated from group discussion indicated & 5 \\
\hline & 8 & Proper precision of data & 5 \\
\hline & 9 & Summary group discussion of pre lab procedure & 3 \\
\hline
\end{tabular}


Result and Specific reasons for the errors proposed

Discussion

11 No vague references to error e.g. "human error" or "machine error"

Percent error should be included if possible

12

Results of calculations and error analysis summarized in a clearly labeled table

13 Provide an answer to the purpose

Research proposal describes the lab that could lead to better results

Conclusion

14 Improvable procedure discussed and revised if necessary

Variables (independent, dependent, constant) for this test were described

${ }^{\mathrm{a}}$ Total $=60$ points.

\section{Questionnaires}

A survey was conducted on gifted science students' perceptions about chemistry experiment laboratory and chemistry experiment laboratory notebook after they finished science high school and went on to continue their advanced education in colleges and universities.

Students were surveyed on their perceptions about chemistry experiment laboratory and chemistry experiment laboratory notebook, when the gifted science students became university students. Survey of students' perceptions of chemistry lab have been revised and supplemented to be used as a personal e-mail survey and telephone interview (Del Carlo et al., 2006; Del Carlo \& Bonder, 2004; Olivier et al., 2001). Survey questions stemmed from issues that arose from observation notes and included 16 questions in four formats: four multiple choice, three Likert scale, two yes/no, and seven open-ended (Appendix 1). In 2006, $11^{\text {th }}$ grade gifted science students who used laboratory notebook for three practical experiments in a chemistry experimental class were given a questionnaire to solicit their opinions and experience using the e-mail after the gifted science students became university students.

\section{Semi-structured interviews}

Questionnaires and semi-structured interviews were used. Based on the relationship between the MAA scores and chemistry experimental laboratory notebook scores, students were divided into four different levels, Four gifted science students, each representing a different level, were given a semi-structured interview by using cellular phone. Cellular phone interviews were recorded and transcribed using the voice recording function of Anycall SCH-W460 model, Samsung Electronics. In order to examine students' perceptions of chemistry laboratory notebook, a semi-structured interview guide was developed and recommended for interview protocol. Data during the pilot study helped to revise the interview guide. The interview guide includes questions about the processes students used in order to write laboratory notebooks, students' current and past experiences with laboratory notebooks, and students' views about the role of the laboratory notebook (Appendix 2).

\section{RESULTS AND DISCUSSION}

\section{Correlation between MAA Score and HGS Score for Chemistry Experiment}

In this study, we tried to find out the following two correlations: (i) Correlation between the MAA scores and the HGS scores, and (ii) Correlation between the MAA scores and the LNR scores. The correlation of coefficients between the MMA scores and HGS scores are shown in Table 3. 
Table 3. Correlation of MAA ${ }^{a}$ and HGS $^{b}$ score for the chemistry experiment

\begin{tabular}{|c|c|c|c|c|}
\hline Class & Factor score & Mean & Standard deviation & Correlation coeff. \\
\hline $1 \mathrm{st}$ & MAA & 84.72 & 12.63 & \multirow{2}{*}{$0.657^{*}$} \\
\hline$(n=13)$ & HGS & 14.62 & 0.36 & \\
\hline 2nd & MAA & 84.16 & 15.17 & \multirow{2}{*}{$0.554^{*}$} \\
\hline$(n=18)$ & HGS & 14.28 & 0.67 & \\
\hline $3 r d$ & MAA & 84.72 & 13.80 & \multirow{2}{*}{-0.065} \\
\hline$(n=15)$ & HGS & 14.47 & 0.52 & \\
\hline 4th & MAA & 87.96 & 9.72 & \multirow{2}{*}{0.108} \\
\hline$(n=17)$ & HGS & 14.32 & 0.61 & \\
\hline 5 th & MAA & 87.92 & 9.27 & \multirow{2}{*}{-0.203} \\
\hline$(n=14)$ & HGS & 14.50 & 0.52 & \\
\hline
\end{tabular}

$\overline{\mathrm{a}}$ Total $=100,{ }^{\mathrm{b}}$ Total $=15.0,{ }^{*} p<0.05$.

The HGS scores had a small standard deviation. The correlation coefficient between the MAA and the HGS score was $+0.657,+0.554,-0.065,+0.108,-0.203$ in order of $1 \mathrm{st}, 2 \mathrm{nd}, 3 \mathrm{rd}, 4 \mathrm{th}$, and 5 th class, respectively. There is a positive correlation coefficient between the MAA scores and chemistry experimental laboratory notebook scores evaluated as HGS in 1st, 2nd, and 4th class, and a negative correlation coefficient in 3rd, 5th class. The 1st and the 2nd classes showed significant correlations at $p=0.05$.

\section{Correlation between MAA Score and LNR Score for Chemistry Experiment}

The correlation coefficient between the MAA score and LNR score is shown in Table 4.

Table 4. Correlation of MAA ${ }^{a}$ score and $L^{2} R^{b}$ score for the chemistry experiment

\begin{tabular}{ccccc}
\hline Class & Factor score & Mean & Standard deviation & Correlation coeff. \\
\hline $\begin{array}{c}1 \text { st } \\
(n=13)\end{array}$ & MAA & 84.72 & 12.63 & $0.675^{*}$ \\
\hline 2nd & LNR & 138.54 & 18.81 & $0.491^{*}$ \\
$(n=18)$ & LNA & 84.16 & 15.17 & 15.88 \\
\hline 3 rd & MAA & 128.44 & 13.80 & 0.078 \\
$(n=15)$ & LNR & 84.72 & 6.05 & 0.277 \\
\hline 4 th & MAA & 133.53 & 9.72 & 17.47 \\
$(n=17)$ & LNR & 87.96 & 9.37 & 0.005 \\
\hline 5 th & MAA & 130.24 & 10.45 & \\
\hline
\end{tabular}

$\overline{\mathrm{a}}$ Total $=100,{ }^{\mathrm{b}}$ Total $=180,{ }^{*} p<0.05$.

As shown in Table 4, the correlation coefficient between the MAA and LNR score was $+0.675,+0.491,+0.078,+0.277$, +0.005 in order $1 \mathrm{st}, 2 \mathrm{nd}$, 3rd, 4th, and 5th class. A close inspection shows that gifted science students who obtained higher MAA scores obtained somewhat higher chemistry experimental LNR scores in 1st, 2nd, and 4th class. The 1st and the 2nd classes showed significant correlations at $p=0.05$.

Gifted science students who obtained higher MMA score did not obtain the higher LNR scores in the 3rd and 5th classes. The degree of relationship between the MAA and LNR score was more direct than the degree of relationship between the MAA and HGS score (Table 5). Relationships between MAA scores and the LNR scores are more correlated than the MAA scores and the HGS scores (Figure 1). 
Table 5. Correlation coeff. of MAA, HGS and LNR score $(\mathbf{N}=77)$

\begin{tabular}{cccc}
\hline Factor score & MAA & HGS & LNR \\
\hline MAA & 1.000 & & 1.000 \\
\hline HGS & $0.236^{*}$ & 1.000 & $0.506^{* *}$ \\
\hline LNR & $0.328^{* *}$ & & \\
\hline${ }^{*} p<0.05,{ }^{* *} p<0.01$. & &
\end{tabular}

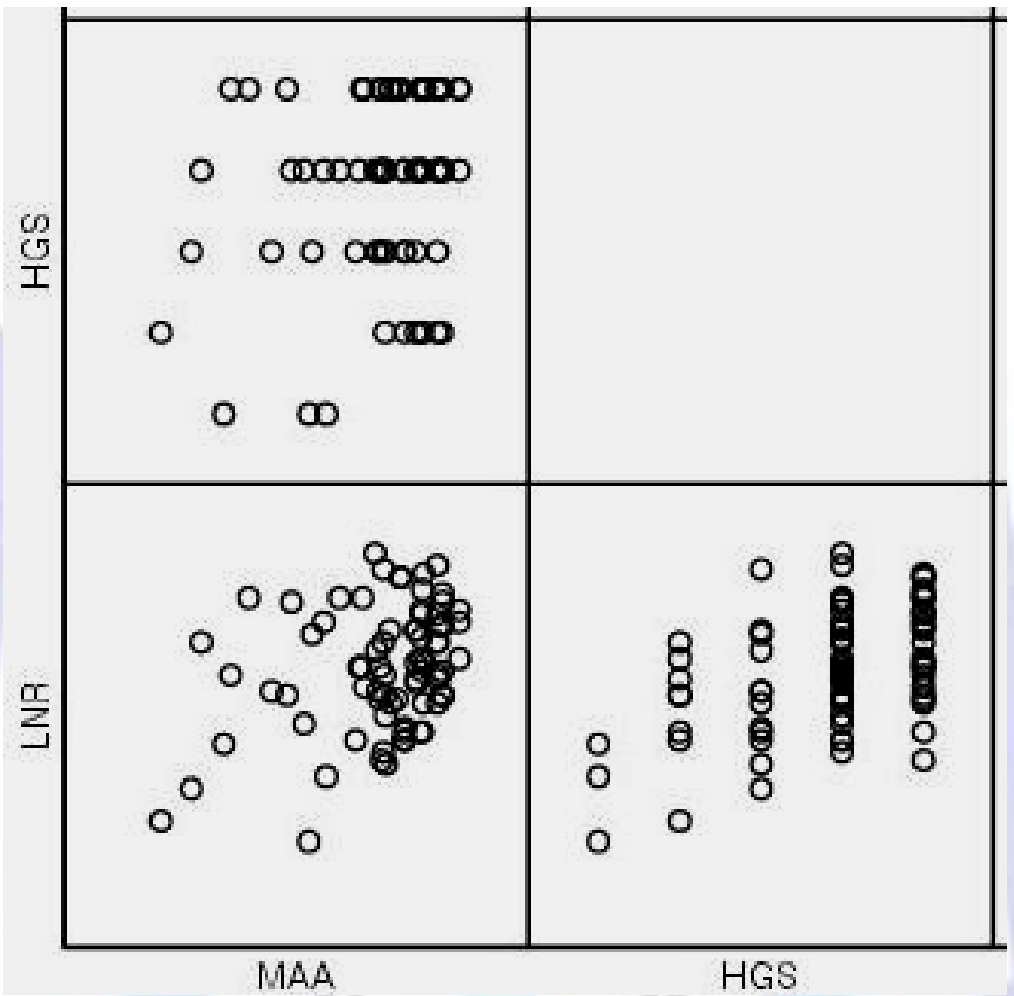

Figure 1. Matrix of MAA, HGS and LNR score $(\mathbf{N}=\mathbf{7 7})$.

On the basis of the mean of MAA and LNR score, the gifted science students can be classified into 4 levels: (i) high MAA/high LNR level students (36\%), (ii) high MAA/ low LNR level students (30\%), (iii) low MAA/ high LNR level students (14\%), and (iv) low MAA/ low LNR level students (19\%) (Figure 2). 


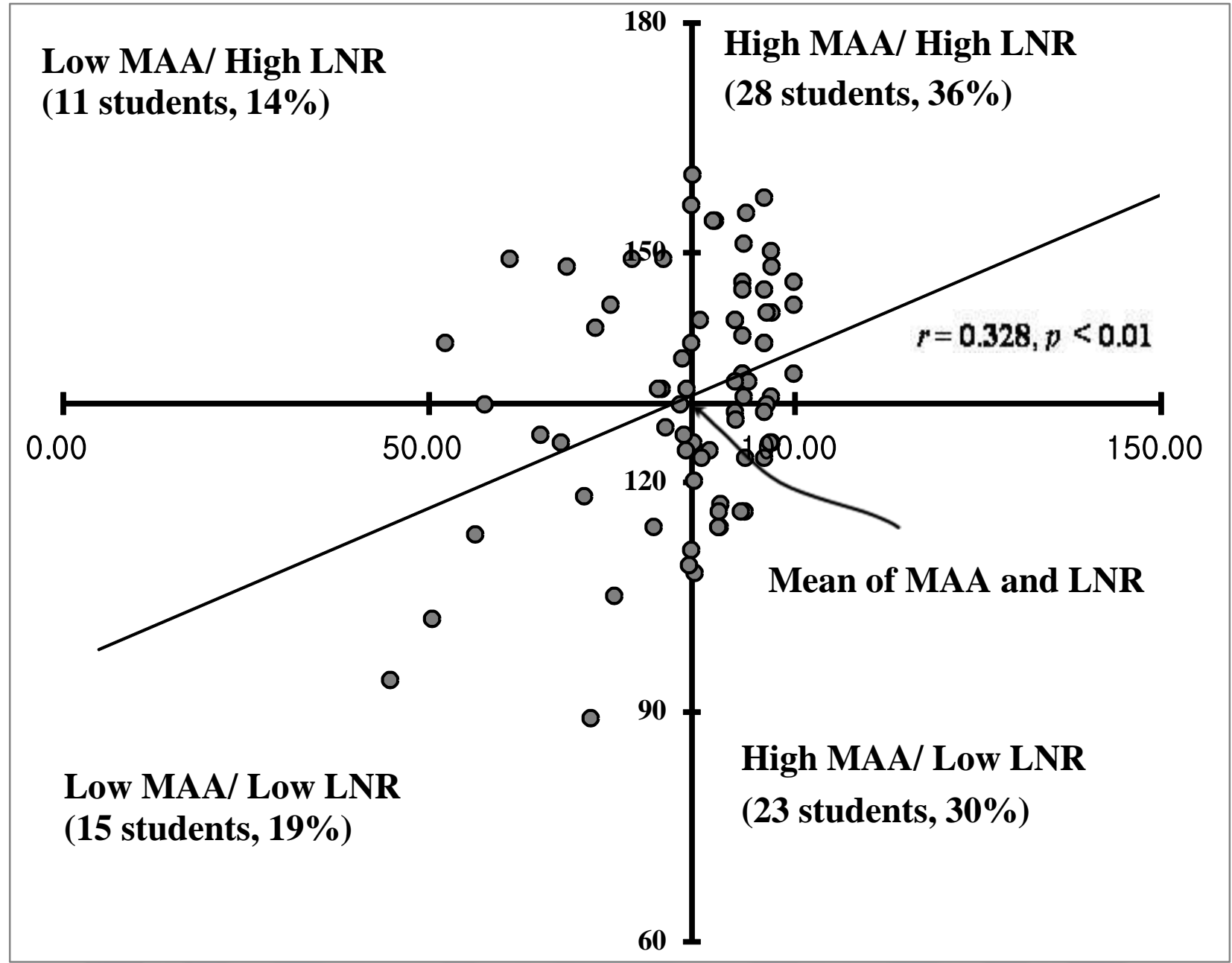

Figure 2. Four types of MAA score and LNR score $(N=77$, MAA score mean $=85.89$, LNR score mean $=130.30)$.

A student classified as having a high MAA/ high LNR level laboratory notebook could logically described the scientific error analysis and was able to interpret the resulting data. A high MMA/ low LNR level student's laboratory notebook was simplistic in error analysis and interpretation of the resulting data and the student had a poor motivation in writing the laboratory notebook. The low MMA/ high LNR level student had good motivation and wrote the laboratory notebook. Also, he thought logically in writing the laboratory notebook. The low MAA/low LNR level student's laboratory notebook was simply written with respect to recording the error analysis and interpreting the resulting data and the student had a poor motivation in writing the laboratory notebook.

\section{The Students' Perceptions of the Chemistry Experiment}

For an e-mail questionnaire survey, the questionnaire was sent to fifty-four gifted science students, and twelve students $(22 \%)$ responded with a completed questionnaire.

The responses to question 1 on the types of chemistry classes they took revealed the following: AP Chemistry course, 6 students; KChO (Korea Chemistry Olympiad) Summer/Winter School, 2 students.

Question 2 asked for what they thought was the-most important thing they learned from chemistry laboratory. Nine students replied that accuracy measuring of variables is the most important in obtaining accurate data. Three other students replied that speed of measuring, especially fast measuring, is most important because everything has to be completed in 2-hour limit. When something goes wrong during the experimental procedure, most of them (10 students) did the lab again to make sure that they get the credit for the laboratory work. Gifted science students thought that they gained a good understanding of experimental procedures and data analysis by doing laboratory experiments.

Responding questions 5, 6 and 7 about the time limit of laboratory work, 58\% stated that the laboratory time was insufficient to complete the laboratory experiments and $42 \%$ stated that they have 5-10 min. free time after the laboratory is finished. During free time, $50 \%$ recorded the experimental results into the laboratory notebook, $33 \%$ talked to other students, $8 \%$ helped work from another group and $8 \%$ arranged neatly experimental apparatus only when they had enough time. On the question asking how hard they worked in their group to answer the Lab questions, the gifted science students scored an average of 3.75 on a scale of 1-5. 
When working in groups, 8 students have never copied another group members' answers. The remaining four students said they have copied answers from other groups. When someone was copying their lab work, their feelings were in the order of "It Depends (5 students)", "Don't Care / It's Ok (3 students)"and "Don't Like It / It's Wrong (1 student)". If they belong to the same group, they answered that copying from the same group members is "all right" since they are doing the same work for a common grade anyway. Only one student said he did not like to see his work being stolen because he has put a lot of time into it.

Some found it meaningful to verify a chemical concept, others liked to analyze errors, still others enjoyed working with various materials, and a few students liked thinking about the conclusions and talking it over with their lab partners. They thought there was a need for an orientation on safety in the lab as well as a need for better apparatus and equipment. Chemistry laboratory must improve safety in the design of open laboratories. All heating, ventilating and air conditioning outlets need to be carefully coordinated so that they do not create cross drafts across the face openings of major exhausts and containment devices (Baum \& DiBerardinis, 2006).

\section{The Students' Perceptions of Chemistry Experiment Laboratory Notebook}

To the question "How difficult is it to write the laboratory notebook on a scale of 1 5?", the students' responses indicated a degree of difficulty of 2.7. The students thought that writing the lab notebook is valuable for the systematic and permanent recording of chemistry experiments. Some students felt the need to improve the chemistry laboratory notebook by requiring students to record the lab date, lab materials and experimental procedures in detail. On a scale of 1 5, Gifted science students gave a mean importance of 3.9 to the role of the lab notebook in the chemistry laboratories. Gifted science students thought that the role of the lab notebook is to keep students from making up data. They believed that the lab notebook helps scientists to record data systematically and generate creative achievement in scientific experiments because the lab notebook allows for the verification of evidence as well as supplying a base for prediction.

\section{Interview of Students' Perceptions of Chemistry Experiment and the Laboratory Notebook}

Based on the relationship between the MAA scores and LNR scores, students may be divided into four different group levels. Four gifted science students, one from each of the four levels identified above, were surveyed in a semi-structured interview by cellular phone (Table 6). The interview focused on the students' perceptions about chemistry laboratories and the laboratory notebook.

Table 6. Gifted science student for telephone interview

\begin{tabular}{|c|c|c|c|c|c|}
\hline $\begin{array}{c}\text { Student } \\
\text { (fictitious) }\end{array}$ & Major & University & $\begin{array}{c}\text { MAA score } \\
(\text { Mean }=85.90)\end{array}$ & (Me & $\begin{array}{l}\text { ore } \\
0.76)\end{array}$ \\
\hline Kim & Medical school (junior) & Seoul National University & 93.20 & 151 & High \\
\hline Jo & $\begin{array}{c}\text { Biological sciences } \\
\text { (sophomore) }\end{array}$ & $\mathrm{KAIST}^{\mathrm{a}}$ & م & 125 & Low \\
\hline Kang & Mechanical engineering & $\begin{array}{c}\text { Sungkyunkwan } \\
\text { University }\end{array}$ & Low & 138 & High \\
\hline Lee & $\begin{array}{c}\text { Mathematical sciences } \\
\text { (junior) }\end{array}$ & $\mathrm{KAIST}^{\mathrm{a}}$ & 71.40 & 118 & Low \\
\hline
\end{tabular}

${ }^{a}$ Korea Advanced Institute of Science \& Technology.

According to the interview of a gifted science student (Kim) who had high MAA/ high LNR level, she took more than one hour to write her chemistry experimental laboratory notebook. She thought that her laboratory notebook was logically written. Kim answered that it is important to record the results of chemistry experiments in the laboratory notebook.

Researcher: What's your opinion on writing the lab notes in the science high school?

Kim: I think it's absolutely necessary. If you don't write the laboratory notebook, you will gain nothing and you will have nothing left at the end of the chemistry laboratory.

Researcher: What experimental courses did enroll in at the university?

Kim: I have signed up for chemistry experiment.

Researcher: How do you turn in the chemistry lab report?

Kim:

I wrote the lab report in longhand and turned it in.

Researcher: Did you describe the experimental procedure and method, too? 
Kim:

Yes.

Researcher:

Did you write it in your lab notebook?

Kim:

They have a lab report form, and I wrote everything in that report form.

Researcher: What do you think of writing the lab report on a word processor?

Kim: $\quad$ I think it's better to write the experimental results in longhand, Handwriting is more helpful for lab report writing. I think the word processor would be better for writing about the theoretical background.

According to interview of gifted science student (Jo) had high MAA/ low LNR score, he took the 0.5 1.0 hour to write his chemistry experimental laboratory notebook. He thought that the laboratory notebook must have written in handout to prohibit from making up data, copying another group's data and to help understanding laboratory.

Researcher: What did you think of the lab note writing you did in your science high school days?

Jo:

Whether you write it on a word processor or your write it in long hand does not make really much difference. Maybe you can save time by writing the lab report on the word processor because it is faster, but the lab notebook is easy to carry it with you to wherever you want to go and jot it down whenever you come upon an idea.

Researcher: What experiment courses are you enrolled in at the university?

Jo: I have signed up for chemistry lab and physics lab.

Researcher: How did you write your lab reports?

Jo:

I had to write the physics lab report on word processor because there were many graphs and a lot of materials involved. I could not use the word processor for the chemistry lab report. There is a chemistry lab report form and I wrote it in longhand.

Researcher: I see.

Jo:

By the way, people don't like plagiarism or maneuvering the data in the lab like the case of Professor $\mathrm{H}$. Longhand writing of the lab note seems to prevent plagiarism because you write it directly with your pen. When you use the word processor to write the experimental method, you tend not to read the content carefully as you copy and attach materials using the keys like Ctrl $\mathrm{C}$ and Ctrl V. But I think I understand the content better if I write it in longhand. Especially in writing the conclusion, I get to find out the cause of errors better when I write it using a pen. Hand writing seems to keep me away from copying other people's data.

According to interview of gifted science student (Kang) had low MAA/high LNR score, he took the about 2.0 hour to write his chemistry experimental laboratory notebook. He thought that the laboratory notebook's experience in science high school helped studying at the university. As his opinion, the chemistry experimental laboratory notebook, would generate the ability to analyze errors and to think rationally.

Researcher: Did the lab note writing in high school days help you any at the university?

Kang: I did not realize it at the time, but now I know that high school lab note writing is helping me a lot. Writing the lab report on the word processor is good because it's fast. But writing it in longhand is better because you can take time to think about the data and organize them carefully.

Researcher: What lab courses did you sign up for?

Kang: I signed up for physics lab.

Researcher: How did you write the lab report?

Kang: In the first semester, I wrote the preliminary lab report and the final report on the word processor, but in the second semester I wrote them in longhand.

Researcher: Why?

Kang: $\quad$ Because the kids copy the lab reports at the college, too.

Researcher: Really?

Kang: $\quad$ Everybody copied in the first semester. Then the Lab assistant told us to write it in longhand for the second semester. I think writing the lab notes is good because it gives you an ability to analyze the differences between what you said you would do in the purpose statement and what you got in the experimental result. The lab note writing also makes you think rationally.

Researcher: What do you think of the lab note writing you did in your high school days? 
Kang: $\quad$ The high school experience of writing the lab note in longhand is helping me a lot in writing the college lab reports. It was not easy learning how to write a good lab notebook at high school, but I think it is worth the time and effort.

According to interview of gifted science student (Lee) had low MAA/ low LNR score, he took the about 0.5 hour to write his chemistry experimental laboratory notebook. Because he had prepared the $\mathrm{KMO}$ (Korea Mathematics Olympiad), he roughly had written his chemistry experimental laboratory notebook. Because of his major in mathematical science, he had forgotten the laboratory notebook in university.

Researcher: What do you think of the lab notes writing you did in your science high school days?

Lee : I l liked math. I did not take it seriously, and I wrote it simply to meet the requirement.

Researcher: Are you taking any lab courses at the university?

Lee: I haven't signed up for any lab courses because department of mathematics does not require lab courses and I don't have to write any lab reports.

According to the results of the semi-structured interview, the gifted science students think that the chemistry experimental laboratory notebook has helped them to think logically and analytically. They had a positive perception for writing the chemistry experimental laboratory notebook in the science high school and university.

\section{CONCLUSION}

These results led us to conclude that educational institutions of gifted science need to evaluate their chemistry laboratory notebooks using a rubric scale. If the development and application of the LNR is to continue, chemistry teachers must promote the high reliability and validity of the rubric in measuring student's abilities in chemistry experiments.

First, the correlation between the MAA scores and chemistry laboratory notebook scores was evaluated both on a HGS scale and on a detailed LNR scale. The degree of relationship between the MAA score and the LNR scores was more direct than that between the MAA scores and the HGS scores. Therefore, the chemistry laboratory notebooks should be evaluated using the detailed LNR scale. The relationship between the MAA scores and the LNR scores allowed gifted science students to be grouped into 4 levels; (i) high MAA/ high LNR score, (ii) high MAA/ low LNR score, (iii) low MAA/ high LNR score, and (iv) low MAA/ low LNR score. High MAA/ high LNR level student's laboratory notebook was logically written, recording scientific error analysis and interpreting of resulting data. High MMA/ low LNR level student's laboratory notebook was simply written, recording error analysis and interpreting of resulting data. He is poorly motivated in writing his laboratory notebook. Low MMA/ high LNR level student's laboratory notebook was simply written, recording error analysis and interpreting the resulting data. He is well motivated in writing his laboratory notebook. Also, he thought logically while writing the laboratory notebook. Low MAA/ low LNR level student's laboratory notebook was simply written, recording the error analysis and interpreting the resulting data. He had poor motivation in writing his laboratory notebook.

Secondly, after graduating from high school and now attending universities for advanced college education, the former gifted science students agreed that accuracy was the most important aspect of a chemistry laboratory. They thought that they gained a better understanding of experimental procedures and data analysis thanks to doing laboratory experiments. Even during their breaks in labs, they were busy collecting data. Most gifted science students did not copy another group members' data and never fabricated data. They were able to do well in advanced courses and acquired an ability to solve the laboratory problems. When gifted science students became university students, four gifted science students, each from a different group, were interviewed. They thought that the instructions for the laboratory notebook should include a rule against fabricating the data and plagiarism, preventing them from copying another group's data, which would be helpful in understanding laboratory work better. They thought that their experience in writing the high school laboratory notebook helped them prepare for college entrance examination. One student commented that "When we write the chemistry laboratory notebook, we sharpen our ability to analyze errors and think rationally." According to the results of the semi-structured interview, the gifted science students thought that the chemistry laboratory notebook helped them think scientifically and to think logically. They have a positive perception of the chemistry laboratory notebook both in science high school and in university.

Based on the findings of this study, we recommend that the chemistry laboratory should be considered with the following insights. In order to attain the maximum benefit from the chemistry laboratory notebook, an educational institution of gifted science students should evaluate the chemistry laboratory using an LNR scale. If the development and application of the LNR is to continue, chemistry teachers must promote the chemistry experiment with a laboratory rubric of high reliability and validity. Applying the detailed laboratory rubric will help improve laboratory experiments in educational institutions of gifted science students.

\section{REFERENCES}

[1] American Association for the Advancement of Science (AAAS) (1990). Project 2061: Science for All Americans. Washington D.C., U.S.A.: AAAS Publication.

[2] Baird, D. C. (1995). Experimentation: An introduction to measurement theory and experiment design (3rd ed.). New York, U.S.A.: Prentice Hall.

[3] Baum, J. S., \& DiBerardinis, L. J. (2006). Open laboratories: Operational and safety issues or how to determine if open laboratories will work for you. Journal of Chemical Health \& Safety, 13(January/February), 15-19.

[4] Beall, H., \& Trimbur, J. (2001). A short guide to writing about chemistry (2nd ed.). Addison-Wesley, U.S.A.: Longman, 
63-64.

[5] Berg, C. A. R., Bergendahl, V. C. B., Lundberg, B. K. S. (2003). Benefiting from an open-ended experiment? A comparison of attitudes to, and outcomes of, an expository versus an open-inquiry version of the same experiment. International Journal of Science Education, 25, 351-372.

[6] Bowen, G. M., Roth, W. M., \& McGinn, M. K. (1999). Interpretation of graphs by university biology students and practicing scientists: Toward a social practice view of scientific representation practices. Journal of Research in Science Teaching, 36, 1020-1043.

[7] Cacciatore, K. L., \& Sevian, H. (2006). Teaching laboratory notebook writing through inquiry: A green chemistry stoichiometry experiment for general chemistry. Journal of Research in Science Teaching, 83, 1039-1041.

[8] Del Carlo, D. I., \& Bonder, G. M. (2004). Students' perceptions of academic dishonesty in the chemistry classroom laboratory. Journal of Research in Science Teaching, 41, 47-64.

[9] Del Carlo, D. I., Mazzaro, D., \& Page, S. (2006). High school students' perceptions of their laboratory classroom and the copying of laboratory work. Journal of Chemical Education, 83, 1362-1367.

[10] Dodd, J. S., Ed. (1997). The ACS style guide: A manual for authors and editors (2nd ed.). Washington, D. C., U.S.A.: American Chemical Society.

[11] Doran, R. L., Chan, F., \& Tamir, P. (1998). Science educator's guide to laboratory assessment. Washington, D. C., U.S.A.: National Science Teachers Association.

[12] Eisenberg, A. (1982). Keeping a laboratory notebook. Journal of Chemical Education, 59, 1045-1046.

[13] Ferzli, M., Carter, M., \& Wiebe E. (2005). LabWrite: Transforming lab reports from busy work to meaningful learning opportunities. Journal of College Science Teaching, 35, 31-33.

[14] Goodman, W. D., \& Bean, J. C. (1983). A chemistry laboratory project to develop thinking and writing skills. Journal of Chemical Education, 60, 483-484.

[15] Greenstadt, M. J. (1978). The care and feeding of gifted students: A personal approach. Journal of Chemical Education, 55, 533-535.

[16] Kanare, H. M. (1985). Writing the laboratory notebook. Washington D. C., U.S.A.: American Chemical Society.

[17] Keys, C. W. (2000). Investigating the think processes of eighth grade writers during the composition of a scientific laboratory report. Journal of Research in Science Teaching, 37, 676-690.

[18] Keys, C. W. (1999). Revitalizing instruction in scientific genres: Connecting knowledge production with writing to learn in science. Science Education, 83, 115-130.

[19] Keys, C. W., Hand, B., Prain, V., \& Collins, S. (1999). Using the science writing heuristic as a tool for learning from laboratory investigations in secondary science. Journal of Research in Science Teaching, 36, 1065-1084.

[20] Kim, D. H., Kang, K. H., \& Park, H. J. (2009). Concerns of science teachers on science-gifted education centers of the Seoul metropolitan office of education. Journal of the Korean Association for Research in Science Education, 29, 90-105 (written in Korean).

[21] Lang, Q. C., Wong, A. F. L., \& Fraser, B. J. (2005). Student perceptions of chemistry laboratory learning environments: Student-teacher ininiactions and attitudes in secondary school gifted education clanmentin Singapore. Research in Science Education, 35, 299-321.

[22] Lazarowitz, R., \& Tamir, P. (1994). In D. Gabel (Ed.), Research on using laboratory instruction in science. Handbook of Research on Science Teaching and Learning, (pp. 94-128). New York: Macmillan.

[23] National Research Council (1996). National science education standards. Washington, DC., U.S.A.: National Academy Press.

[24] National Research Council (2000). Inquiry and the national science education standards: a guide for teaching and learning. Washington, D. C., U.S.A.: National Academy Press.

[25] Olivier, G. W. J., Herson, K., \& Sosabowski, M. H. (2001).Web mark-a fully automated method of submission, assessment, grading, and commentary for laboratory practical scripts. Journal of Chemical Education, 78, 1699-1703.

[26] Shiland, T. W. (1999). Constructivism: The implications for laboratory work. Journal of Chemical Education, 76, 107-109.

[27] Um, M. J. (2007). Recommendation of basic plan for developing human resources in science and technology: The 2nd basic plan in science and technology (human resources part). STEPI Policy Research Reports 2007-15. Seoul, South Korea: Science and Technology Policy Institute (written in Korean).

[28] Vázquez, A. V., McLoughlin, K., Sabbagh, M., Runkle, A. C., Simon, J., Coppola, B. P., and Pazicni, S. (2012). Writing-To-Teach: A new pedagogical approach to elicit explanative writing from undergraduate chemistry students. Journal of Chemical Education, 89, 1025-1031.

[29] Wimpfheimer, T. (2004). Peer-evaluated poster sessions: An alternative method to grading general chemistry laboratory work. Journal of Chemical Education, 81, 1775-1776.

\section{Appendix 1. Questionnaire items (Del Carlo et al., 2006; Del Carlo \& Bonder, 2004)}

1. What type of chemistry class you were taking ?
a) AP Chemistry
b) Korea Chemistry Olympiad Summer School
c) Korea Chemistry Olympiad Winter School 
d) Other

2. When doing a laboratory, what is the most important thing to you?

a) Accuracy, how close are you to get the correct answer.

b) How fast do you finish.

c) Other

3. If something goes wrong while you are doing the procedure, what would you do to make sure you get credit for the laboratory?

4. By doing laboratory experiments, do you think that you get a better understanding of the experimental procedures and data analysis?

Yes No Other

5. After the laboratory is finished, how much free time do you have?
a) Insufficient
b) $5-10 \mathrm{~min}$
c) 20-30 $\mathrm{min}$
d) More than $30 \mathrm{~min}$

6. During this time, what do you do?

a) Finish written work from the laboratory

b) Help work from another group

c) Talk to other students

d) Other

7. On a scale of $1-5$, with 5 being always, how often do you work in a group to answer the laboratory notebook questions?

8. While working in groups, have you ever copied another group members answers? Yes No Other

9. What are your feelings toward someone copying your laboratory work?

10. What is your favorite thing about chemistry laboratories?

11. What is one thing you wish you could change about chemistry laboratories in general?

12. How easy/difficult did you write the laboratory notebook?
(a) very easy
(b) easy
(c) normal
(d) difficult
(e) very difficult

13. How about some the positive use of laboratory notebook is in chemistry experiment?

14. Please tell us your ideas for improving the use of laboratory notebook for chemistry experiment.

15. How do you think about the role of the laboratory notebook in the chemistry experiment laboratory?
(a) very important
(b) important
(c) average
(d) unimportant
(e) very unimportant

16. How about the role of laboratory notebook in science laboratories at the workplace?

\section{Appendix 2. Student interview protocol}

1. Think back to when you were writing the first laboratory notebook for chemistry experiment laboratory, what are some of your feelings at the time?

2. How about writing the lab notes in the science high school??

3. Did you take the experiment courses at the university?

4. Has writing laboratory notebooks helped your understanding of concepts you had to write about?

5. Tell me what you think about the role of the laboratory notebook in school science laboratories. 